\title{
Mulheres negras em situação de refúgio no Brasil: as múltiplas lutas em face da superação das desigualdades
}

\author{
Mujeres negras en situación de refugio en Brasil: las múltiples luchas \\ frente a la superación de las desigualdades \\ Black women in situations of refuge in Brazil: the multiple struggles in the \\ face of overcoming inequalities
}

\author{
Juliana Vital Rosendo 1 \\ Grasielle Borges Vieira de Carvalho ${ }^{2}$ \\ Ronaldo Alves Marinho da Silva ${ }^{3}$ \\ Samyle Regina Matos Oliveira ${ }^{4}$ \\ Verônica Teixeira Marques 5
}

\begin{abstract}
Resumo
O deslocamento de muitas mulheres de seus países de origem para outros, pode estar relacionado a conflitos de guerra, perseguições, situações de extrema pobreza em que as mulheres são as maiores vítimas e por muitas vezes, duplamente violadas. As violências persistem até mesmo durante o deslocamento forçado em que se tornam ou voltam a ser vítimas de violência sexual, agressões, assédio, dentre outras violações. Tal situação torna-se ainda mais grave quando voltamos o olhar para as mulheres negras, que passam a dispor de diversos fatores contrários à sua inserção no meio social, dentre os quais podemos citar: a questão de gênero, o status de "refugiada", além da raça. Segundo estudos realizados, dentre as vítimas do refúgio, as meninas e mulheres representam as parcelas com o menor índice de acesso ao sistema educacional; e no que diz respeito à parcela da população negra, esse índice é ainda menor, o que acaba por refletir na futura inserção no mercado de trabalho. Dessa forma, entendemos que é indispensável uma atuação efetiva por parte do Estado, bem como da sociedade civil, no que se refere ao investimento em políticas de inserção dessas mulheres nos campos educacionais e trabalhistas, como forma de empoderá-las e tornar possível a superação da situação de vulnerabilidade em que se encontram. O trabalho tem como principal finalidade discutir os instrumentos que devem ser implementados como meio de possibilitar a inserção dessas mulheres no meio social, a fim de lhes proporcionar uma vida digna, de efetivação dos seus direitos, superação das violências sofridas e rompimento com as desigualdades.
\end{abstract}

Palavras-Chave: Brasil; Mulher; Negra; Refúgio; Violência.

\section{Resumen}

El desplazamiento de muchas mujeres de sus países de origen a otros puede estar relacionado con conflictos de guerra, persecuciones, situaciones de extrema pobreza en las que las mujeres son las mayores víctimas y muchas veces doblemente violadas, pues las violencias persisten incluso durante el desplazamiento forzado, en que se

\footnotetext{
${ }^{1}$ Doutoranda em Direito Político e Econômico pela Universidade Presbiteriana Mackenzie; São Paulo, São Paulo, Brasil; julianavrosendo@ hotmail.com.

${ }^{2}$ Doutora em Direito Político e Econômico pela Universidade Presbiteriana Mackenzie; São Paulo, São Paulo, Brasil; grasiellevieirac@gmail.com.

${ }^{3}$ Doutorando em Direito Político e Econômico pela Universidade Presbiteriana Mackenzie; São Paulo, São Paulo, Brasil; ronaldo_marinho@outlook.com.br.

${ }^{4}$ Mestre em Ciência Jurídica pela Universidade Estadual do Norte do Paraná; Jacarezinho, Paraná, Brasil; samyle.adv@gmail.com.

${ }^{5}$ Doutorado em Ciências Sociais pela Universidade Federal da Bahia; Salvador, Bahia, Brasil; veronica.marques@hotmail.com.
} 
vuelven o vuelven a ser víctimas de violencia sexual, agresiones, acoso, entre otras violaciones. Pero esta situación se vuelve aún más grave cuando volvemos la mirada a las mujeres negras, que pasan a disponer de diversos factores contrarios a su inserción en el medio social, entre los cuales podemos mencionar: la cuestión de género, el status de "refugiada, además de la raza. Según estudios realizados, entre las víctimas del refugio, las niñas y las mujeres representan las parcelas con el menor índice de acceso al sistema educativo; y en lo que se refiere a la parte de la población negra, ese índice es aún menor, lo que finalmente refleja en la futura inserción en el mercado de trabajo. De esa forma, entendemos que es indispensable una actuación efectiva por parte del Estado, así como de la sociedad civil en lo que condice a la inversión en políticas de inserción de esas mujeres en los campos educativos y laborales, como forma de empoderarlas y hacer posible la superación de la situación de vulnerabilidad en que se encuentran. El trabajo tiene como principal finalidad, discutir los instrumentos que deben ser implementados como medio de posibilitar la inserción de esas mujeres en el medio social, con el fin de proporcionarles una vida digna, de cumplimiento de sus derechos, superación de las violencias sufridas y rompimiento con las mismas desigualdades.

Palabras claves: Brasil; Mujer; Negra; Refugio; Violencia.

\section{Abstract}

The displacement of seberal women from their original countries to other nations may be related to war conflicts, persecution, extreme poverty situations, of which women are the bigget victims and are, in several occasions, doubly violated sice violence continues even along the forced displacement they must endure, during which time they either become or go back into becoming visctims of sexual abuse, aggression, harrassment, among other kinds of violation. Such situation becomes even more severe when we cast our look to black women who face many obstacles against their incclusion in society, such as the gender issue, the "refugee" status, as well as the race problem. According to some studies, among the displaced victims, girls and women represent the ones who achieve the lowest rate in terms of access to educational systems. When it comes to the black population, that rate gets even lower, resulting in difficulties towards future labor market inclusions. Therefore, we see it as a must that both the State and the civil society act together in order to effectively promote investment in inclusion policies, so that these women will be empowered enough to have access to education and so be able to join the work force, thus freeing themselves from the situation of vulnerability they are in. The main objective of this article is to discuss the tools to be put into effect in order to help promote the inclusion of these women in society so that they may enjoy a decent life, which includes the confirmation of their rights, the suppression of violence against them, as well as the end of unequalities.

Keywords: Brazil; Woman; Black; Refuge; Violence.

\section{Introdução}

Diante do grande fluxo migratório existente em todo o mundo, medidas voltadas à assistência dessas vítimas precisam ser tomadas. A mera incorporação de instrumentos legais não configura como suficientes para atender às especificidades existentes. São pessoas oriundas de diversos países, com cultura, idioma, língua, realidades completamente divergentes das existentes nos locais em que procuraram reconstruir suas vidas, e que necessitam de meios concretos para superar as adversidades nas quais se encontram.

As mulheres negras refugiadas, por exemplo, são vítimas de diversas violações de direitos. Violações essas que iniciam antes mesmo do descolamento (quando são impedidas de ter acesso ao sistema educacional, são vítimas de mutilações genitais, perseguições motivadas por gênero, raça, religião); nos campos de refúgio são vistas como objetos sexuais, 
e finalmente, a falta de assistência nos países que supostamente estariam preparados para acolhê-las.

O presente trabalho tem justamente o intuito de discutir as dificuldades encontradas pelas mulheres negras refugiadas ao chegar em solo brasileiro. Vítimas de múltiplas violências e com necessidades/demandas especiais motivadas por fatores que são considerados impeditivos ao seu fortalecimento social e econômico, essas mulheres demandam políticas assistências que venham proporcionar a sua reinserção.

Dessa forma, o trabalho discutirá brevemente as dificuldades enfrentadas por esse grupo, bem como a importância da implementação de políticas voltadas ao campo educacional e trabalhista, sejam elas oriundas exclusivamente da atuação do Poder Estatal ou em parceira, como instrumentos fundamentais na superação da violência e situação de vulnerabilidade na qual estão inseridas.

\section{As mulheres negras em situação de refúgio face as múltiplas violências}

Numericamente, as mulheres não representam o maior quantitativo dentre as pessoas que se encontram em situação de refúgio, mas configuram como as vítimas que demandam necessariamente uma maior atenção diante da situação de vulnerabilidade pela qual se encontram. O deslocamento do seu país de origem em direção a um novo local para moradia, representa a medida encontrada para superar as perseguições políticas, religiosas, de gênero/raça, desastres ambientais, situações de guerra, dentre outros fatores, nos quais se encontravam anteriormente.

Nos últimos sete anos, o Brasil contabilizou 126.102 solicitações de refúgio, só em 2017, foram 33.866. Do total de refugiados reconhecidos no país, as mulheres representam $29 \%,{ }^{6}$ em que o perfil etário que mais se destaca corresponde à faixa entre 30 e 59 anos. Nenhum país da América Latina figura dentre os dez países ${ }^{7}$ com o maior número de refugiados reconhecidos no Brasil. Porém, a Venezuela foi a que apresentou, no ano de 2017, o maior quantitativo de solicitações de reconhecimento da condição de refugiado, com 53\% (ALTO COMISSARIADO DAS NAÇÕES UNIDAS PARA REFUGIADOS, 2018).

Contando com diversos fatores contrários à sua inserção no meio social e no mercado de trabalho, como por exemplo o status de "refugiada", a questão do gênero, bem como de

\footnotetext{
${ }^{6}$ Não são apresentados dados referentes ao quantitativo de mulheres negras refugiadas.

${ }^{7}$ São eles: Síria, República Democrática do Congo, Palestina, Paquistão, Egito, Iraque, Mali, Líbano, Camarões e Guiné.
} 
raça, as mulheres negras são as que mais sofrem violência, apresentam menor índice de acesso ao sistema educacional e ingresso no mercado de trabalho. Ou seja, estão mais propensas a sofrer diversos tipos de violações devido as suas "características".

São vários os motivos que contribuem para a instauração e manutenção da desigualdade educacional de meninas negras, pontos esses que podem estar relacionados: à discriminação baseada no sexo (pois, em muitos países os pais entendem como preferível investir na educação dos meninos, enquanto as meninas desenvolvem as atividades do lar e de cuidado de irmãos/irmãs mais novos); ao casamento precoce (saem do ambiente escolar para dedicar-se às atividades domésticas); tais fatores podem aparecer ainda de forma conjugada, como a questão da pobreza, idioma e o acesso aos centros educacionais (NAÇÕES UNIDAS, 2018). ${ }^{8}$

No caso das meninas refugiadas, o acesso é interrompido por conta do deslocamento forçado e, posteriormente, da dificuldade de adaptação ao ambiente do novo país (seja por questões culturais, de idioma, falta de políticas de acesso ao sistema educacional). Consequentemente, a falta de ensino básico acaba por refletir, posteriormente, de forma negativa na vida dessas meninas/mulheres, limitando ainda mais o acesso ao mercado de trabalho, a participação na vida econômica e social.

A dificuldade de participação da mulher no mercado de trabalho e na vida econômica do país configura como uma das problemáticas a serem enfrentadas ao redor do mundo, e quando adicionados a questão de raça e o status de refugiada, referida inserção torna-se ainda mais difícil. No Brasil, a diferença de rendimento entre homens e mulheres é de $\mathrm{R} \$ 542,00$ (no caso das mulheres negras o rendimento é ainda menor). As mulheres dedicam 18,1h a afazeres domésticos/cuidados de pessoas (negras/pardas - 18,6, brancas - 17,7) enquanto os homens dedicam apenas 10,5h semanais (INSTITUTO BRASILEIRO DE GEOGRAFIA E ESTATÍSTICA, 2018).

São exemplos como os apresentados anteriormente que corroboram com a necessidade de criação, implementação e fiscalização de medidas/políticas voltadas à assistência de mulheres negras refugiadas no país, pois essas vítimas dispõem de diversos fatores contrários à sua reinserção social, à reconstrução de suas vidas em um país cuja cultura, idioma, costumes divergem largamente do seu local de origem. São mulheres que deixaram toda uma vida para trás e necessitam de meios que possibilitem o seu fortalecimento social, econômico,

\footnotetext{
${ }^{8}$ A título exemplificativo, em países como a Uganda, Etiópia e Quênia, os três que mais recebem refugiados na África, as estudantes mulheres têm $50 \%$ menos chance do que os homens de frequentar o ensino fundamental II e o ensino médio (MENINAS ..., 2018).
} 
trabalhista. É importante destacar ainda, que não podemos generalizar quanto a falta de acesso ao sistema educacional e a qualificação profissional, pois em alguns casos, o que falta na verdade, é oportunidade; é conseguir aproveitar os benefícios que a diversidade pode proporcionar.

\section{A importância das políticas públicas como compromisso estatal}

É notória a conexão entre a política pública e a garantia dos direitos fundamentais sociais, de natureza prestacional (positiva), isso porque a primeira funciona como meio para efetivação dos últimos. Desse modo, segundo Samyle Oliveira (2017, p. 22-23), o reconhecimento formal dos direitos fundamentais no ordenamento jurídico de cada país está relacionado com a sua forma de Estado. Nesse sentido:

\section{(...) o reconhecimento dos direitos fundamentais em textos constitucionais, ou seja, a sua positivação, asseverou que estes eram ou pelo menos deveriam ser para todos. Sobretudo após os embates entre o liberalismo conservador e o socialismo totalitário, tornou-se possível, ainda que formalmente, a compatibilização dos direitos à liberdade e à igualdade. Assim, a "incorporação da classe trabalhadora no sistema parlamentar representativo" possibilitou a abertura aos novos direitos, transformando o "Estado de Direito em Estado Social de Direito" (AMARAL apud OLIVEIRA, 2017, p. 22).}

No tocante ao papel assumido pelo Estado, vale frisar que as mudanças das formas de Estado também viabilizaram a relevância, sobretudo, dos direitos fundamentais à democracia e à liberdade. No Estado Social, a democracia teve o papel de ser "o mais fundamental dos direitos da nova ordem normativa que se assenta sobre a concretude do binômio igualdade-liberdade" (BONAVIDES apud OLIVEIRA, 2017, p. 22-23), isso porque com a democracia a sociedade ganha voz e representatividade.

[...] a democracia é o direito do povo, de reger-se sobre sua vontade e mais do que forma de governo se converte, sobretudo, em pretensão da cidadania; a titularidade direta e imediata do poder, subjetivado juridicamente na consciência social e efetivado de forma concreta pelo cidadão, em nome, em proveito da sociedade e não do Estado propriamente dito - quer o Estado Liberal que separa poderes, quer o Estado Social, que monopoliza competências, atribuições e prerrogativas (BONAVIDES apud OLIVEIRA, 2017, p. 25).

Assim, o próprio Estado passa a estabelecer uma relação simbiótica com os direitos fundamentais, posto que "o Estado de Direito exige e implica, para sê-lo, a garantia dos direitos fundamentais, ao passo que estes exigem e implicam, para sua realização, o reconhecimento e a garantia do Estado de Direito" (LUÑO apud OLIVEIRA, 2017, p. 25). 
Pode-se dizer, portanto, que a reconciliação da sociedade com o Estado, propicia o quadro indispensável ao florescimento de uma liberdade que tem por manivela do sistema jurídico, as garantias sociais e processuais de sua concretização e somente pode se desenvolver, segundo Bonavides, sob a égide do Estado Social (BONAVIDES apud OLIVEIRA, 2017, p. 25).

Em outras palavras, a sociedade passou, então, a exercer um papel fundamental no que diz respeito à efetivação dos direitos fundamentais e na configuração dos direitos humanos. Hoje, há uma evidente preocupação em dar concretude aos princípios por meio dos quais se expressam os direitos humanos, atribuindo-se a estes não apenas um caráter programático, mas reconhecendo a sua juridicidade. Dessa forma, conceber a garantia dos direitos fundamentais é, na verdade, uma proteção, mediata, o que significa dizer que se realiza por meio de um instrumento: o direito. Essa é a razão pela qual se defende que os direitos fundamentais necessitam de um aparato normativo de ordem Constitucional para aspirarem à eficácia (OLIVEIRA, 2017, p. 17).

Nas palavras de Sarlet (apud OLIVEIRA, 2017, p. 24), os direitos fundamentais compõem "ao lado da definição da forma de Estado, do sistema de governo e da organização do poder, a essência do Estado Constitucional”, fazendo parte da Constituição formal e assumindo o papel de "elemento nuclear da Constituição material”.

A partir dessa afirmação também é possível dizer que as políticas públicas sustentam-se nos direitos fundamentais ao mesmo tempo em que são mecanismos úteis à concretização dos mesmos, estabelecendo, desse modo, uma relação de dependência.

A "política" acompanhada do adjetivo "público" remete para quem esta deve ser direcionada, isto é, para a coletividade. Com efeito, "Uma política é pública quando contempla os interesses públicos”. Nesse contexto, dada a extrema relevância que a questão dos objetivos sociais ganha em na definição de políticas públicas é que se torna possível compreender a perspectiva do Eduardo Appio (apud OLIVEIRA, 2017, p17 ) quanto ao fato de que os aglomerados urbanos e o processo de industrialização foram fenômenos que geraram a necessidade de políticas públicas, isso porque com esses adventos a classe trabalhadora, sobretudo, necessitava da garantia de direitos sociais. Portanto, para este autor, as políticas públicas exigem uma combinação de vontade pública e conhecimento técnico, atuando como instrumentos estatais de intervenção na economia e na vida privada, consoante limitações e imposições previstas na própria Constituição. Além disso, as políticas públicas "podem ser vistas também como processo ou conjunto de processos que culmina na escolha racional e coletiva de prioridades, para a definição dos interesses públicos reconhecidos pelo 
direito" ou, ainda, podem ser entendidas "como forma de controle prévio de discricionariedade na medida em que exigem a apresentação dos pressupostos materiais que informam a decisão, em consequência da qual se desencadeia a ação administrativa" (BUCCI apud OLIVEIRA, 2017, p17).

\section{Políticas assistenciais como instrumentos de superação e empoderamento}

O Brasil representa um dos destinos mais procurados pelos refugiados, o qual é signatário de diversos tratados internacionais que versam sobre a temática dos Direitos Humanos, bem como constitui parte integrante na Convenção das Nações Unidas sobre o Estatuto dos Refugiados, além de ter promulgado em julho de 1997, a Lei do Refúgio (Lei 9.474/97). Lei que traz em seu bojo questões voltadas às características necessárias para a configuração do status de refugiado, versando ainda sobre suas condições jurídicas, pedido de refúgio, dentre outros. Mas o ponto que merece destaque, corresponde à criação do CONARE (Comitê Nacional para os Refugiados), visando ampliar o aparato de assistência aos refugiados no país. Mas diante do exposto, resta saber se o país está de fato estruturado para receber as vítimas de refúgio (ROSENDO; OLIVEIRA, 2017).

É perceptível que o país não dispõe de condições/meios adequados para receber os refugiados, em especial as mulheres, que apresentam necessidades específicas que precisam ser atendidas, como por exemplo, instrumentos que possam acolher seus filhos enquanto trabalham, pois muitas vezes se deslocam, sem nenhum familiar. Assim, entendemos como necessária a incorporação de medidas nos mais diversos âmbitos, seja ele educacional, trabalhista, da saúde, que possibilite a reconstrução da vida dessas mulheres. É indispensável a parceira entre Estado e sociedade na busca de criar e fortalecer instrumentos de empoderamento e superação das desigualdades nas quais estão inseridas.

O Estado brasileiro conta atualmente com programas promovidos pela Agência da ONU para Refugiados, ONU Mulheres, Cátedra Sérgio Vieira de Mello, dentre outras instituições, voltadas para a criação de programas/políticas educacionais e trabalhistas. Citamos como exemplo o projeto "Empoderando Refugiadas" (workshops educacionais e trabalhistas) e a atuação da Cátedra com algumas universidades do país no sentindo de facilitar o ingresso dos refugiados às instituições de ensino superior, bem como a revalidação do diploma (PROJETO ..., 2017; ALTO COMISSARIADO DAS NAÇÕES UNIDAS PARA REFUGIADOS, 2017). Recentemente, mais especificamente; em julho de 2018, foi sancionada no Rio de Janeiro a Lei $\mathrm{n}^{\circ} 8.020$ (lei estadual), que isenta os refugiados que 
moram no estado, do pagamento de taxas de revalidação de diplomas de graduação, mestrado e doutorado nas universidades estaduais (RIO ..., 2018).

Dentre os instrumentos assistenciais mapeados, apenas um deles está voltado para as mulheres refugiadas, ou seja, é o único que considera as especificidades apresentadas por esse grupo. O "Empoderando Refugiadas", deve ser visto como um exemplo de política a ser desenvolvida em todas as localidades do país, levando sempre em consideração as necessidades dos grupos que vão ser atendidos pelo projeto. Se o grupo é composto majoritariamente por mães, faz-se necessário a criação de locais de acolhimento para filho/filhas; ou no caso de não dominarem o idioma local, desenvolver aulas voltadas ao aprendizado da língua portuguesa. A partir do momento em que o país se compromete a receber pessoas em situação de refúgio, migração, deslocamento forçado, ele precisa criar meios que venham a atender suas necessidades.

\section{Conclusões}

O quadro crescente de refugiados e solicitantes de refúgio no Brasil exige uma resposta mais eficaz por parte do país. Quando analisadas as políticas/instrumentos existentes de acolhimento percebe-se que o número não é suficiente para atender a demanda apresentada, situação que se torna ainda mais preocupante quando voltamos o foco para as políticas assistenciais para as mulheres, grupo que possui especificidades e, por conta disso, demanda um acolhimento diferenciado.

Como discutido ao longo do trabalho, os motivos para o deslocamento são diversos, e as violências sofridas são múltiplas, violações que continuam a acontecer, de forma diferenciada, no novo país de moradia: dificuldades de acesso ao sistema educacional (para mulheres e crianças), ao mercado de trabalho, na participação econômica. Realidade encontrada por mulheres brancas e negras, mas que no caso dessas últimas, a situação é ainda mais grave devido ao fator "raça" estar somado ao fator de "gênero" e ao status de "refugiada".

Por isso, torna-se imprescindível o olhar diferenciado para esse grupo. É preciso incentivar a criação de projetos que promovam o aprendizado do idioma e da cultura local, facilitação e isenção de taxas referentes a revalidação de diplomas, ingresso diferenciado nas universidade e escolas públicas. Já que através de meios como os apresentados cria-se aos poucos, formas de superação das dificuldades enfrentadas. Mas não podemos esquecer do papel social no acolhimento e rompimento dos paradigmas existentes quanto à mulher negra e refugiada. 


\section{Referências}

ALTO COMISSARIADO DAS NAÇÕES UNIDAS PARA REFUGIADOS. Ministério da Justiça. Secretaria Nacional de Justiça. Refúgio em números. 2018. Disponível em: <http://www.acnur.org/portugues/wp-content/uploads/2018/04/refugio-emnumeros_1104.pdf>. Acesso em: 29 jun. 2018.

Relatório Anual 2017 - Cátedra Sérgio Vieira de Mello. 2017. Disponível em: $<$ http://www.acnur.org/portugues/wp-content/uploads/2018/02/Cátedra-Sérgio-Vieira-DeMello_Relatório-Anual_ACNUR-2017.pdf>. Acesso em: 24 jun. 2018.

INSTITUTO BRASILEIRO DE GEOGRAFIA E ESTATÍSTICA. Estatísticas de Gênero Indicadores sociais das mulheres no Brasil. 2018. Disponível em: <https://biblioteca.ibge.gov.br/visualizacao/livros/liv101551_informativo.pdf>. Acesso em: 6 jul. 2018.

MENINAS refugiadas têm menos acesso à educação por serem mulher, diz ONU. Nações Unidas do Brasil, 8 mar. 2018. Disponível em: <https://nacoesunidas.org/meninasrefugiadas-tem-menos-acesso-a-educacao-por-serem-mulher-diz-onu/>. Acesso em: 02 jul. 2018 .

NAÇÕES UNIDAS. Mulheres e meninas afrodescendentes - Conquistas e desafios de Direitos Humanos. 2018. Disponível em: <https://nacoesunidas.org/wpcontent/uploads/2018/03/18-0070_Mulheres_e_Meninas_Afrodescendentes_web.pdf $>$. Acesso em: 2 jul. 2018.

OLIVEIRA, Samyle Regina Matos. A Política Criminal do Brasil e sua efetividade por meio das Políticas Públicas. Dissertação (Mestrado em Ciência Jurídica) - Universidade Estadual do Norte do Paraná, Jacarezinho-PR, 2017.

PROJETO "Empoderando Refugiadas" promove oportunidades educacionais entre refugiadas no Brasil. Organização das Nações Unidas Mulheres, 17 maio 2017. Disponível em: <http://www.onumulheres.org.br/noticias/projeto-empoderando-refugiadas-promoveoportunidades-educacionais-entre-refugiadas-no-brasil/>. Acesso em: 1 jul. 2018.

RIO aprova isenção de taxas para revalidação de diplomas de refugiados. Nações Unidas do Brasil, 6 jul. 2018. Disponível em: <https://nacoesunidas.org/rio-aprova-isencao-de-taxaspara-revalidacao-de-diplomas-de-refugiados/>. Acesso em: 15 jul. 2018.

ROSENDO, J. V.; OLIVEIRA, L. P. S. Mulheres invisibilizadas: uma análise das políticas de assistência e acolhimento as vítimas de refúgio. In: VIEIRA, Reginaldo de Souza; TEIXEIRA, Marcio Aleandro Correia (Coord). Direitos sociais e políticas públicas II. Florianópolis: CONPEDI, 2017. Disponível em: <https://www.conpedi.org.br/publicacoes/27ixgmd9/7hf15gnq/D48k692on8jYg26P.pdf >. 
RELACult - Revista Latino-Americana de Estudos em Cultura e Sociedade

Revista Latinoamericana de Estudios en Cultura y Sociedad | Latin American Journal of Studies in Culture and Society V. 05, ed. especial, mai., 2019, artigo $\mathrm{n}^{\circ}$ 1515 | claec.org/relacult | e-ISSN: 2525-7870

Acesso em: 29 jun. 2018. 